\title{
PREVALENCE AND HEALTH SEEKING BEHAVIOR AMONG SPECIFIC WOMEN GROUP ON REPRODUCTIVE TRACT INFECTION IN RURAL COMMUNITY AREA OF KANCHEEPURAM DISTRICT, TAMIL NADU: A CROSS SECTIONAL STUDY REPORT
}

\author{
SUJA SURESH ${ }^{1}$, S. ARUNA ${ }^{2}$ \& G. VALLI ${ }^{3}$ \\ ${ }^{I}$ Associate Professor, Community Health Nursing Department, Billroth College of Nursing, Chennai, India \\ ${ }^{2} \operatorname{MSc}(N)$., PhD., Reader, HOD., Community Health Nursing Department, Sri Ramachandra College of Nursing, Sri \\ Ramachandra University, Chennai, India
}

${ }^{3}$ PhD, Professor \& HOD., Department of Pharmacology, Meenakshi Ammal Dental College, Maduravoyal, Chennai, India

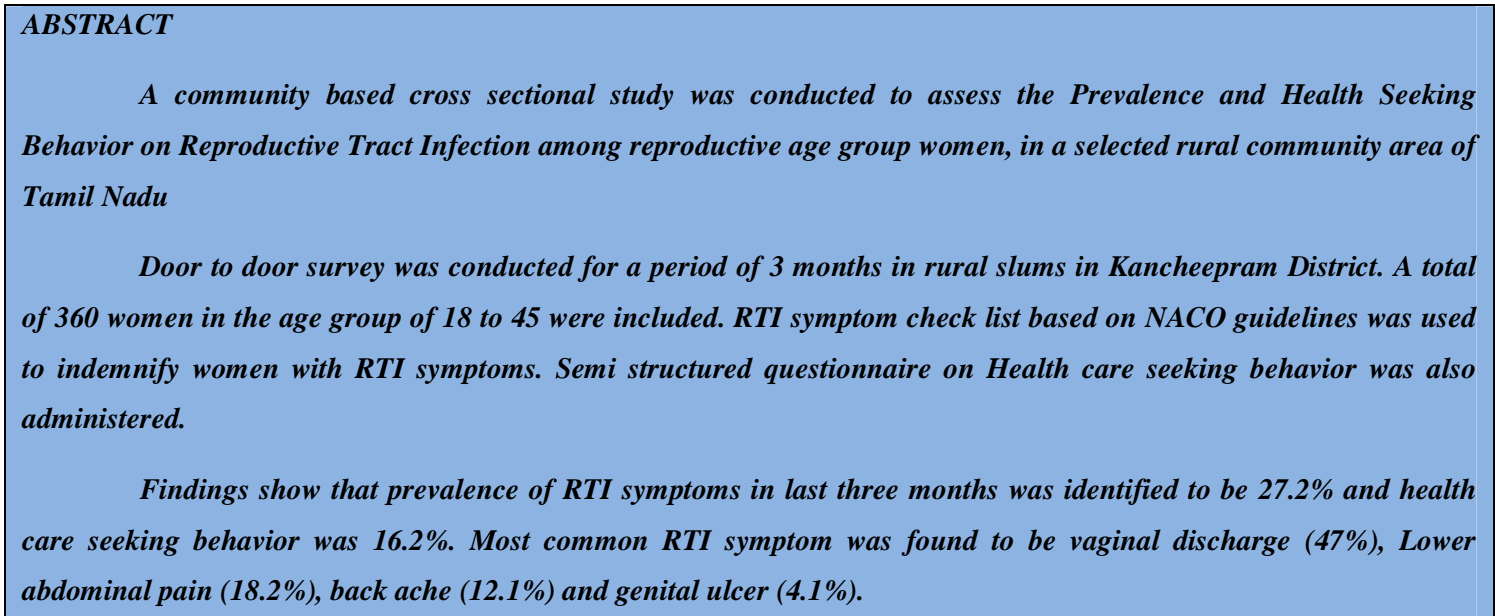

Door to door survey was conducted for a period of 3 months in rural slums in Kancheepram District. A total of 360 women in the age group of 18 to 45 were included. RTI symptom check list based on NACO guidelines was used to indemnify women with RTI symptoms. Semi structured questionnaire on Health care seeking behavior was also administered.

Findings show that prevalence of RTI symptoms in last three months was identified to be $27.2 \%$ and health care seeking behavior was $16.2 \%$. Most common RTI symptom was found to be vaginal discharge (47\%), Lower abdominal pain (18.2\%), back ache (12.1\%) and genital ulcer (4.1\%).

KEYWORDS: Reproductive Tract Infection \& Health Seeking Behavior

Received: Jun 14, 2017; Accepted: Jun 29, 2017; Published: Jul 03, 2017; Paper Id.: IJMPSAUG20171

\section{INTRODUCTION}

Reproductive tract infection (RTI) is a group of infectious diseases caused due to bacterial, virus, fungi and other pathogens that invades the genital tract. This can cause serious physical and psychological complication to the women. This can also increase the vulnerability to HIV/AIDS. [1] RTI represents a foremost public health issue in developing countries. Every year, more than a million women and infants die of the complications of RTI. [2]

RTI has become a epidemic that devastates women's lives.[2] These include, post abortal and puerperal sepsis, ectopic pregnancy, fetal and perinatal death, and infertility; chronic lower abdominal pain, emotional distress social rejection of women and cervical cancer. Some of the RTIs act as precursors for cancer cervix as reported in different studies, and thus may require prompt treatment.[3] Each year nearly 1.3 million women die of reproductive health problems that are largely preventable and 1 out of 20 teenagers contract a sexually transmitted 
disease, some of which causing lifelong disabilities such as infertility or death.[4]

\section{Significance and Need for the Study}

In India, the prevalence of self reported STI/RTI among 15- 45yrs found to be $21.9 \%$. Most of the available data on RTI are from hospital and clinical based, and community based studies are less commonly conducted. But, it gives better estimate of prevalence. RTI ranges from $39 \%$ to $84 \%$ in India. [5]

Women themselves are largely reluctant to discuss about RTI/STDs with others. Social stigma attached to illnesses is somewhat greater for women, therefore, women is most likely to hide her illness. The problem of RTI/STD morbidity among women is largely due to ignorance, low level of awareness on sexual and reproductive health and social factors like low female literacy, cultural factors - all with holding the women seeking health care from RTI and STDs.

The investigator noticed during her service in the rural community areas, women were suffering with RTI, to best of my knowledge there was no statistical evidence on burden of RTI in selected community area. Though RTI is considered as significant medical problem among women only few studies have been carried out in the community. Hence, the researcher aimed to identify the prevalence of RTI and assess their health seeking behavior among reproductive age group women in this geographical area.

\section{OBJECTIVES}

To assess the Prevalence and Health Seeking Behavior on Reproductive Tract Infection among Reproductive age group Women in a Selected Rural Community Area of Kancheepuram District, Tamil Nadu.

\section{RESEARCH METHODOLOGY}

A community based cross sectional study was done in the rural slum areas of kancheepuram District. To conduct the research, investigator obtained "Institutional Ethical Committee clearance certificate and official written permission from Director of Public Health. Written consent letter was received from all the participants. 2 clusters were chosen out of 19 villages from the PHC which comes under the selected community area. Total of 360 women in the age group 18-45 were included in the study. Based on the sample size calculation, the sample size was arrived at 300, assuming $20 \%$ attrition, which led to 360 samples from 2 clusters. House to house survey was done in selected clusters. From each cluster, 130 samples were included based on inclusion criteria (permanently residing married women in selected villages under Kundrathur PHC, women with RTI symptoms between the age group 18 - 45 years, those who know Tamil language, accepted to participate in the study).

The researcher developed the structured questionnaire based on RTI based on WHO syndromic approach, to assess baseline variables, RTI symptoms like excessive vaginal discharge, lower abdominal pain, dysuria, dysparunia, low back pain, itching and burning sensation in genital area, ulcer in vulva, painful swelling in groin. To asses health seeking behavior structured questionnaire was used. It was reviewed and validated by the experts. The tool was developed in English and translated in Tamil. Congruencies were maintained after the translation. Reliability of the instrument was established and validated by test retest method $(\mathrm{r}=0.88)$. Therefore the instrument was considered to be reliable.

The data was collected by the investigator in their homes, after obtaining informed concern. Pre-tested and predesigned structured questionnaire was used to identify the presence of RTI as per the NACO guidelines among the married women. RTI was said to present, if the women reported any one of the symptom under WHO (World health 
Prevalence and Health Seeking Behavior among Specific Women Group on Reproductive

Tract Infection in Rural Community Area of Kancheepuram

District, Tamil Nadu: A Cross Sectional Study Report

organization) syndromic approach. Then, the respondents were asked about health care seeking behavior and baseline variables.

\section{RESULTS}

In the present study, demographic information of married women reveled that in relation to age of the married women, most of them belong to 18-26 years (43.3\%), majority of the married women were living with their husband, and only $8 \%$ of them are separated. Majority of them were house wives and following nuclear family pattern. Most of them were not having previous knowledge on RTI (96.7\%).

Table 1: Prevalence of RTI among Married Women

\begin{tabular}{|c|c|c|c|}
\hline $\begin{array}{c}\text { No. of women } \\
\text { screened }\end{array}$ & $\begin{array}{c}\text { Number of married } \\
\text { women having RTI }\end{array}$ & $\begin{array}{c}\text { Percentage of women } \\
\text { with RTI }\end{array}$ & $\begin{array}{c}\text { 95\% Confidence } \\
\text { interval }\end{array}$ \\
\hline 360 & 90 & $25.1 \%$ & $22.8 \%-32.0 \%$ \\
\hline
\end{tabular}

The above table shows, among the 360 married women in reproductive age group were screened for symptoms, 90 of them reported one or the other symptoms of RTI. So the prevalence of RTI based on the symptoms, was found to be $25.1 \%(95 \%$ CI: $22.8 \%-32.0 \%)$.

Most common RTI symptom was found to be vaginal discharge (47\%), Lower abdominal pain (18.2\%), Back ache $(12.1 \%)$, genital ulcer $(4.1 \%)$, dysuria $(9 \%)$, and dysperunia $(3.2 \%)$ respectively.

Table 2: Symptomatic distribution of RTI

\begin{tabular}{|c|c|c|}
\hline & & $\mathrm{N}=90$ \\
\hline Symptoms & Number & Percentage \\
\hline Vaginal Discharge & 42 & $47.0 \%$ \\
\hline Lower abdominal pain & 16 & $18.2 \%$ \\
\hline Back ache & 11 & $12.1 \%$ \\
\hline Genital Ulcer & 4 & $4.1 \%$ \\
\hline Dysuria & 8 & $9.0 \%$ \\
\hline Dysperunia & 3 & $3.2 \%$ \\
\hline $\begin{array}{l}\text { Itching and irritation in genital } \\
\text { area }\end{array}$ & 5 & $5.3 \%$ \\
\hline Inguinal pubo & 1 & $1.1 \%$ \\
\hline
\end{tabular}

Highest prevalence was found in the age group of 18 -26years(43.6\%), lesser prevalence was found in the 36-45 years(10.3\%).The prevalence of RTI decreases with level of education and found to be lowest in among graduates(9.1\%). There was statically significant difference found in the literacy status. The prevalence of RTI was higher among unskilled workers $(58.7 \%)$. 


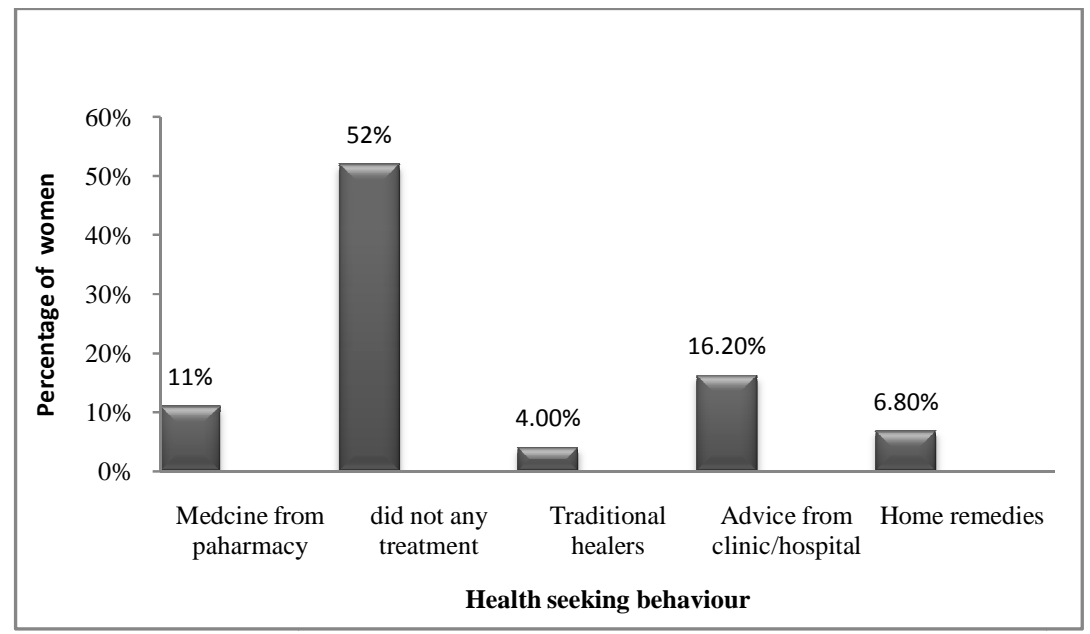

Figure 1: Health Seeking Behaviour of Women on RTI Symptoms

Figure 1 shows health seeking behavior of women on RTI symptoms. Regarding the health seeking behavior $52 \%$ of the symptomatic women did not seek any medical care facilities, $11 \%$ of them sort medical help form the pharmacist, $4 \%$ of them seek help from the traditional healers, $16.2 \%$ of them seek advice and treatment from the government hospital and private hospital. Further, $6.8 \%$ followed home remedies.

\section{DISCUSSIONS}

RTI is more prevalent among younger generation, it was observed among 18-25 years. Mulla et al, also reported in Gujarat out of 150 females with RTI 54.7\% were20- 25 years of age. It is found in the present study, RTI was common among 18-25 years, so it is similar to other studies. [6]

The most common RTI symptoms among married women in the current study was vaginal discharge (47\%), followed by lower abdominal pain (18.2\%). Out of 90 women $57.7 \%$ have one symptom of RTI, and $21.1 \%$ women have more than 2 symptoms of RTI. Parmar T Mehwl (2013) states most common presenting symptom was viginal discharge (36.4\%) followed by burning micturation (24.7\%), lower abdominal pain (13.0\%) and less common was genital ulcer (8.6 \%). [7] B Vuylsteke (2015) reported that the symptomatic approach has been major step forward rationally and improving management of RTI. In present study we followed WHO syndromic approach guidelines to identify the women suffering with RTI.[8]

In the present study, $52 \%$ of the symptomatic women did not seek any medical care facilities, $11 \%$ of them sort medical help form the pharmacist, $4 \%$ of them seek help from the traditional healers, $16.2 \%$ of them seek advice and treatment from the government hospital and private hospital.8.8\% followed home remedies. This was lower than the national (55.6\% and 54.1\%) Behavior Surveillance Survey (BSS) by NACO 2010.

\section{CONCLUSIONS}

Women are residing in slums suffering with RTI and its impact due to ignorance and lack of knowledge. Present study explicit that symptoms suggestive of RTI was found to be higher, and HSB was poor. Results inferred from the cross sectional survey can only give statistical information about RTI and the factors associated, it does not show the cause effect relation so further study can be conducted with Lab investigation. An organized behavior change communication change programme among rural population is need of the hour to control and prevent RTI/STI. 
Prevalence and Health Seeking Behavior among Specific Women Group on Reproductive

Tract Infection in Rural Community Area of Kancheepuram

District, Tamil Nadu: A Cross Sectional Study Report

REFERENCES

1. Patel V.etal.(2006). The Burden and determinants of reproductive tract infection in India. Sex transmission infection, 82(3), 243-9.

2. Bansal KM, Singh K, Bhatnagar S.(2001. Prevalence of lower RTI among married females in the reproductive age group(1545 yrs). Health Popul Perspect Issues,2, 157-63.

3. World Health Organization. Cervical cancer screening programme managerial guidelines. Geneva: WHO; (2000).

4. Issac RC. (2000). An Intervention Programme for RTIs among Women in a Selected Area in Rural Tamil Nadu, India. South East Asian Studies Manual, 112-20.

5. Bang R A, etal.(1989). High prevalence of Gynecological disease in rural Indian Women. Lancet, (1), 85-8.

6. Shethwala N, Mulla S. (2014).Study on RTI among the female patients attending the gynecology OPD in one of the teaching hospital of Gujarath, India.Ind J Med.Sci public health, 3, 123-125.

7. Parmar M T etal.(2013). A study of prevalence of STI and response to syndromic treatment among married women of reproductive age group in rural area of Parol PHC under Thane District.GJMEAPH, 2(2), 1-8.

8. Vuylsteke B. (2004) current status of syndromic management of sexually transmitted infections in developing countries. Sex Transm Infect, 8,333-4 
